\section{Island-hopping invaders hitch a ride with tourists in South Georgia}

Sir - Southern Ocean islands have long been considered to represent globally significant examples of pristine environments, important for the conservation of intact ecosystems. This is about to change because of environmental pressure arising from an escalation of tourism to the region (15,000 tourists in 1999) ${ }^{1}$, marked climate change, and consequent increases in the impacts of invasive species ${ }^{2}$.

Over the past three years, tourism to South Georgia has tripled ${ }^{1}$, and most southern islands now receive such visits. This trend is exemplified by the recent publication of an environmental impact assessment of tourism to Marion Island ${ }^{3}$.

Commissioned by the agency responsible for the island's administration, the South African Department of Environmental Affairs \& Tourism, the impact assessment is a response to increasing demands for tourism. Although citing expert opinion that tourism poses considerable threats to the biota, because it increases the likelihood of invasive species arriving and becoming established, the assessment concludes that, in low numbers, tourism may proceed.

Among several important issues raised by the impact assessment is the compatibility of conservation and access. Just as it is becoming clear that multiple use of protected areas commonly has deleterious effects on biota, the demand for it is becoming more vociferous, and in many instances is entrenched in management policy or laws governing the areas concerned.

Thus, Marion Island was declared a special nature reserve under South Africa's Environment Conservation Act, which in addition to its conservation clauses also specifies that any citizen of the republic wishing to view such an area may do so, at once creating a potential conservation conflict.

The environmental impact assessment also highlights the substantial mitigation costs, usually borne by the responsible authorities rather than the tourist operators, likely to be incurred should an alien species establish itself as a result of tourist activities.

Such activities fall into a high-risk category, because they tend to involve short visits by numerous people who have frequently visited similar islands. This is likely to mean greater propagule pressure than a single landing of a few people who spend an extended time at one island, and is likely to facilitate 'island-hopping' by invasive species.

What makes the Southern Ocean islands particularly significant is that, although their isolation means that species have nowhere to go in the face of human pressure, it also means that conservation problems should be straightforward to manage.

Sadly, the latter seems not to be the case, providing a glimpse into the future as the former becomes true of increasingly fragmented mainland habitats.

Perhaps if tourism were limited now, the islands might provide sight of an alternative where conservation enjoys priority over access.

Steven L. Chown ${ }^{\star}$, Kevin J. Gaston $\dagger$

${ }^{\star}$ Department of Zoology and Entomology,

University of Pretoria, Pretoria 0002, South Africa

$\dagger$ Biodiversity and Macroecology Group,

Department of Animal and Plant Sciences,

University of Sheffield, Sheffield S10 2TN, UK

International Association of Antarctica Tour Operators. http://www.iaato.org/tour_stats.html (2000).

2. Bergstrom, D. \& Chown, S. L. Trends Ecol. Evol. 14, 472-477 (1999).

3. Heydenrych, R. \& Jackson, S. Environmental Impact Assessment of Tourism to Marion Island (Department of Environmental Affairs \& Tourism, Pretoria, 2000).

\section{Status of Japanese monkeys under debate}

Sir - The article "Row over fate of endangered monkeys" (Nature 408, 280; 2000) indicated that Japanese macaques (Macaca fuscata) are listed as an "endangered" animal species.

This information is now out of date. The latest World Conservation Union list, released in October this year, indicates that there are not enough data to qualify the species as endangered. The great majority of Japanese monkeys are not currently listed in any of the World Conservation Union's Red Lists.

In fact, the Japanese monkeys regularly come into conflict with humans - for example, they are agricultural pests to many farmers. As a result, the Environment Agency has granted local governments permission to 'remove' some monkeys. The number of monkeys removed each year is estimated to be 5,000 or more.

Neuroscientists in Japan have obtained only a small fraction of these 'removed' monkeys (about 150 per year); the monkeys would otherwise have been killed. We have never asked for monkeys to be removed solely for research purposes.

The use of animals in research has vastly increased our knowledge of human brain function and malfunction. We emphasize that various lines of experimentation using monkeys, including Japanese monkeys, have played and continue to play a critical role in developing our understanding of the brain.

\section{Kunihiko Obata}

The Japan Neuroscience Society, National Institute for Physiological Sciences, Myodaiji, Okazaki 444-8585, Japan

\section{Call for a fairer deal on grant applications}

Sir-Most UK researchers on short-term contracts, like myself, are called 'research associates', and cannot be the principal applicant (which is understandable) or even a co-applicant (which is much less understandable) on a grant application.

The Biotechnology and Biological Sciences Research Council has a 'recognised researcher' option, but the other UK research councils have no relevant mechanism at all. When it comes to applications for studentships, a research associate cannot even be mentioned.

This situation is doubly upsetting. First, when research associates come up with a good idea for a grant application, they cannot get any benefit from it. More and more universities, when they advertise for lectureships, ask for applicants with proven ability to attract external funding. Being named as a co-applicant for research grants would be useful in this regard as well as providing recognition for the work we do.

Second, university departments are losing the benefit of potential funding, as research associates are increasingly disgusted by the situation and are becoming reluctant to share their ideas with academic staff. Instead, they wait in the hope of obtaining a position that will allow them to apply for grants on their own behalf — not necessarily in the United Kingdom. Of course, some of us still participate in grant applications, but too often our names are not mentioned and we get no credit when a proposal is funded.

By writing this letter, I hope to reach as many research associates as possible, and urge them to put pressure on their supervisors to raise this matter with the UK research councils. The councils need to change their policies on grant-application eligibility in the interests of all. Young researchers should be acknowledged for their efforts, and deserve encouragement rather than being made to feel that the word 'associate' in their title is meaningless.

Robert Dorazi

Department of Biological Sciences, Heriot-Watt University, Edinburgh EH14 4AS, UK 